\title{
PReS-FINAL-2201: A P268S NOD mutation in one Blau patient
}

\author{
M Pardeo ${ }^{1}$, E Cortis ${ }^{2}$, C Bracaglia ${ }^{1}$, R Nicolai ${ }^{1}$, F De Benedetti ${ }^{1}$, A Insalaco ${ }^{\text {* }}$ \\ From 20th Pediatric Rheumatology European Society (PReS) Congress \\ Ljubljana, Slovenia. 25-29 September 2013
}

\section{Introduction}

Blau syndrome (BS) is a rare autosomal dominant, autoinflammatory syndrome characterized by the clinical triad of granulomatous, recurrent uveitis, dermatitis and symmetric arthritis. Arthritis is usually a polyarticular exuberant synovitis and tenosynovitis and represents the characteristic phenotypic feature. Uveitis occurs in most patients and commonly evolves to a panuveitis. In the majority of patients, the disease is characterized by early onset, usually before 3-4years of age. The gene responsible for BS has been identified in the caspase recruitment domain gene NOD2/CARD15, and the most common mutations were found in codon 334 (R334Q and R334W). NOD2 is a member of a family of intracellular proteins with $\mathrm{N}$-terminal caspase recruitment domains (CARDs). Since the first report of an association of the NOD2 variants with Crohn disease by Hugot et al, extensive studies have been focused on an association of NOD2 with inflammatory bowel disease (IBD), pediatric Blau syndrome, NOD2-associated autoinflammatory disease (NAID) and rheumatic disease.

\section{Objectives}

To identify the genotype-phenotype correlation of our patient.

\section{Methods}

We describe a 4-year-old male, the first child of healthy unrelated parents, who presented at 13 months of age, with arthritis of the ankle and of the second proximal inter-phalangeal of the right hand, without the typical puffy appearance. Laboratory test revealed mild increase in inflammatory parametrs (erythrocyte sedimentation rate $35 \mathrm{~mm} / \mathrm{h}, \mathrm{C}$-reactive protein $0.77 \mathrm{mg} / \mathrm{dl}$ ) and the presence of antinuclear antibody (titer 1:640, homogeneous pattern). A diagnosis of ANA positive oligoarticular juvenile idiopathic arthritis was made and an infiltration of the ankle joint with TXA was performed, with insufficient response. Persistence of the ankle arthritis led to initiate treatment with methotrexate that was not associated with clear benefit. Four months later the patient developed recurrent episodes of fever and skin rash on limbs and trunk, with spontaneous resolution, and subsequently recurrent episodes of bilateral anterior uveitis.

\section{Results}

Based on the presence of persistent arthritis, recurrent uveitis, fever and rash, Blau Syndrome was suspected and molecular analysis of NOD2/CARD15 gene was performed. Sequencing analysis demonstrated a heterozygous c.802C $>$ T mutation (P268S/SNP5) in exon 4.

\section{Conclusion}

Until now the c.802C $>\mathrm{T}$ mutation (P268S/SNP5) in exon 4 of NOD2 had only been reported in association with Crohn's disease, rheumatoid arthritis, spondylarthropathy and ulcerative colitis. This is, to the best of our knowledge, the first case of c. $802 \mathrm{C}>\mathrm{T}$ mutation (P268S/SNP5) that appears to be associated with clinical features of Blau syndrome.

\section{Disclosure of interest}

None declared.

\section{Authors' details}

${ }^{1}$ Pediatric Medicine-Rheumatology, Ospedale Pediatrico Bambino Gesù, Rome, Italy. ${ }^{2}$ Pediatric, Ospedale Santa Maria della Stella, Orvieto, Italy. 
- Convenient online submission

- Thorough peer review

- No space constraints or color figure charges

- Immediate publication on acceptance

- Inclusion in PubMed, CAS, Scopus and Google Scholar

- Research which is freely available for redistribution 